\title{
Benefits of Using CBCT in Bilateral Maxillary Impacted Canines Extraction: A Case Report
}

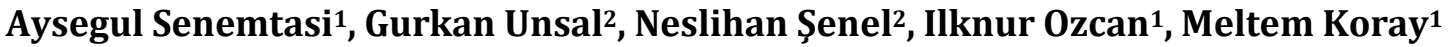 \\ ${ }^{1}$ Istanbul University, Faculty of Dentistry, Department of Oral and Maxillofacial Surgery, İstanbul, Turkey \\ ${ }^{2}$ Istanbul University, Faculty of Dentistry, Department of Oral and Maxillofacial Radiology, İstanbul, Turkey \\ Email: mkoray@istanbul.edu.tr
}

How to cite this paper: Senemtasi, A., Unsal, G., Şenel, N., Ozcan, I. and Koray, M. (2019) Benefits of Using CBCT in Bilateral Maxillary Impacted Canines Extraction: A Case Report. Open Journal of Stomatology, 9, 147-157.

https://doi.org/10.4236/ojst.2019.96015

Received: May 7, 2019

Accepted: June 15, 2019

Published: June 18, 2019

Copyright $\odot 2019$ by author(s) and Scientific Research Publishing Inc. This work is licensed under the Creative Commons Attribution International License (CC BY 4.0).

http://creativecommons.org/licenses/by/4.0/

\begin{abstract}
Aim: Canines are the second most impacted teeth in jaws after third molars. Perforation of the anatomic structures, such as maxillary sinus and nasal fossa, are some of the complications of the surgery. In this case, bilateral maxillary impacted canines' extraction, with the guidance of $\mathrm{CBCT}$ is done without any complication. Case: A 24-year-old female patient was referred to Istanbul University, Oral and Maxillofacial Surgery. Left and right deciduous canines and swelling at the right maxillary canine's labial area were seen during the intraoral examination. Bilateral impacted canines were determined after evaluating the present $\mathrm{CBCT}$ images of the patient and orthodontic treatment was advised to the patient. Due to the refusal of orthodontic treament, extractions of the impacted teeth were decided. After the evaluation of CBCT images, the maxillary right canine was determined at the labial site while the maxillary left canine was determined at the palatinale site. Results: Right maxillary canine was lying between the right first incisor and right first molar and It was extracted with mucoperiosteal vestibule flap procedure. For the extraction, the tooth was divided into two pieces from the enamel-cement junction. Left maxillary canine was lying between the left first incisor and left first molar and It was extracted with mucoperiosteal palatinale flap procedure. Flap was stitched primarly with $3 / 0$ silk sutures. Palatinal plaque, which was prepared before the surgery, was applied. Antibiotic, analgesic and moutwash were prescribed to the patient. 1 week following the surgery, stitches were removed and the healing was optimal. Conclusion: Impacted canines are a common clinic condition which requires a multi-discipliner approach. СBCT can increase the success of the treatment by preventing possible complications with determining the proximity of the anatomical structures and the localization of the impacted teeth. There were no sign of complication and the healing was optimal.
\end{abstract}

\section{Keywords}

Impacted Canine, CBCT 


\section{Introduction}

Maxillary canines, after the third molars, are the most commonly impacted teeth [1]. In general, the causes for retarded eruption of teeth may be either generalized or localized.

Generalized causes include endocrine deficiencies and irradiation, among others. The most common causes for canine impactions are usually localized and are the result of any one or a combination of the following factors: abnormal tooth position of the tooth bud, prolonged retention or early loss of deciduous canine, tooth size-arch length discrepancies, ankylosis, dilaceration of the root, the presence of an alveolar cleft, iatrogenic, trauma [2] [3] [4].

Maxillary canine impaction occurs in $2 \%$ of the population and the incidence ratio of females:males and maxilla:mandible are approximately 2:1 [5]. Approximately one-third of impacted maxillary canines are located labially and two-thirds are located palatally [6] [7].

It is important for surgeons to pay close attention to the presence of neurovascular structures during operations. The anterior maxilla, also called the premaxilla, is usually considered a safe region for surgery. Adjacent anatomical structures need to be thoroughly evaluated prior to interventions such as implant surgery, bone grafting, endodontic surgery, removal of an impacted canine or a supernumerary tooth, orthognathic surgery, and cyst enucleation [8] [9].

The nasopalatine canal and the nasal floor can be easily identified on conventional radiographs and are important anatomical landmarks in the anterior maxilla; however, recent publications have focused on other structures, such as anterior superior alveolar nerve, that should be considered to ensure a relatively safe surgical procedure in this region [10].

The use of cone-beam computed tomography (CBCT) allows a 3-dimensional evaluation of the jaws; thus, surgeons can obtain more detailed and accurate information about the quality and quantity of the bone, helping them to identify anatomical features. Prior to a surgical procedure, a careful preoperative examination is necessary to avoid complications and to take the appropriate precautions. Moreover, less bone loss can be achieved by revealing the exact location and surgical entrance way. More attention should be paid to the detection of small neurovascular bundles to reduce the risk of injury. Surgical manipulation of these bundles can lead to hemorrhage and nerve deficits such as paresthesia, anesthesia, and pain [8] [10] [11] [12] [13].

In this case, the importance of $\mathrm{CBCT}$ guidance in bilateral maxillary impacte canines' extraction is reported.

\section{Case}

A 24-year-old female patient was directed to Istanbul University, Faculty of Dentistry, Department of Oral and Maxillofacial Surgery from a private dental clinic with pre-taken CBCT images for 2 impacted canine's extraction. Left and 
right maxillary deciduous persistent canines and swelling at the right maxillary canine's labial area were seen during the intraoral examination (Figure 1). There was no swelling at the palatal site (Figure 2). Bilateral impacted canines were determined after evaluating the pre-taken CBCT images of the patient (Figure 3) and orthodontic treatment was advised to the patient. The maxillary right canine was determined at the labial site while maxillary left canine was determined at the palatinale site. When the cross-sectional images of the CBCT were examined, it was seen that both the right maxillary canine and the left maxillary canine were in contact with the nasal floor and the maxillary sinus floor and left maxillary canine showed a palatal extension (Figure 4, Figure 5).

Due to the refusal of orthodontic treatment recommendation, extractions of the impacted teeth were decided. Informed consent was taken from the patient and the surgical process is explained to the patient.

Impacted right maxillary canine, which was lying between the right first incisor and right first molar was extracted with mucoperiosteal vestibule flap procedure under local anesthesia. The mucoperiosteal vestibule flap was removed (Figure 6). For the extraction, the tooth was removed by dividing into two pieces from the enamel-cement junction (Figures 7-9).

Impacted left maxillary canine, which was lying between the left first incisor and left first molar, was extracted with mucoperiosteal palatinal flap procedure under local anesthesia. The mucoperiosteal palatinal flap was removed (Figure 10). The tooth was removed by dividing into two pieces from the enamel-cement junction and bone from the palatinal region was also removed (Figure 11). Flaps were stitched primarily with $3 / 0$ silk sutures.

Palatinal plaque, which was prepared before the surgery, was applied (Figure 12). The patient was informed about the possible negative outcomes of using palatinal plaque unless a good oral hygiene is ensured. Antibiotic, analgesic

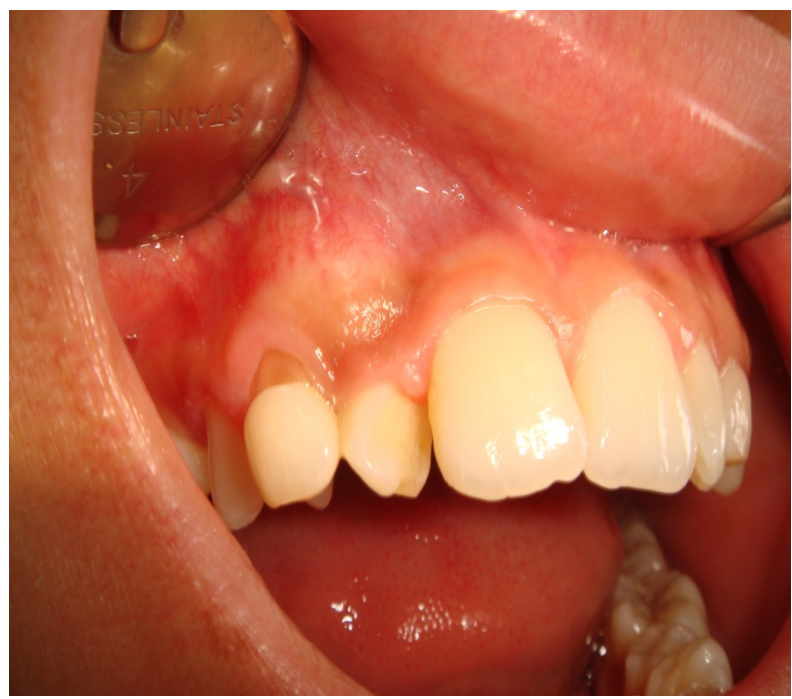

Figure 1. Right maxillary deciduous persistent canine and swelling at the right maxillary canine's labial region. 


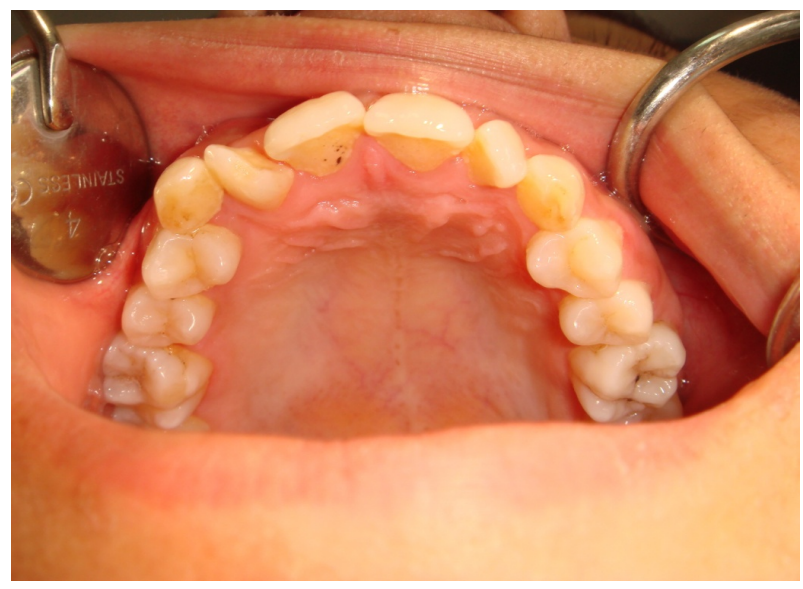

Figure 2. Palatal region of the maxilla.

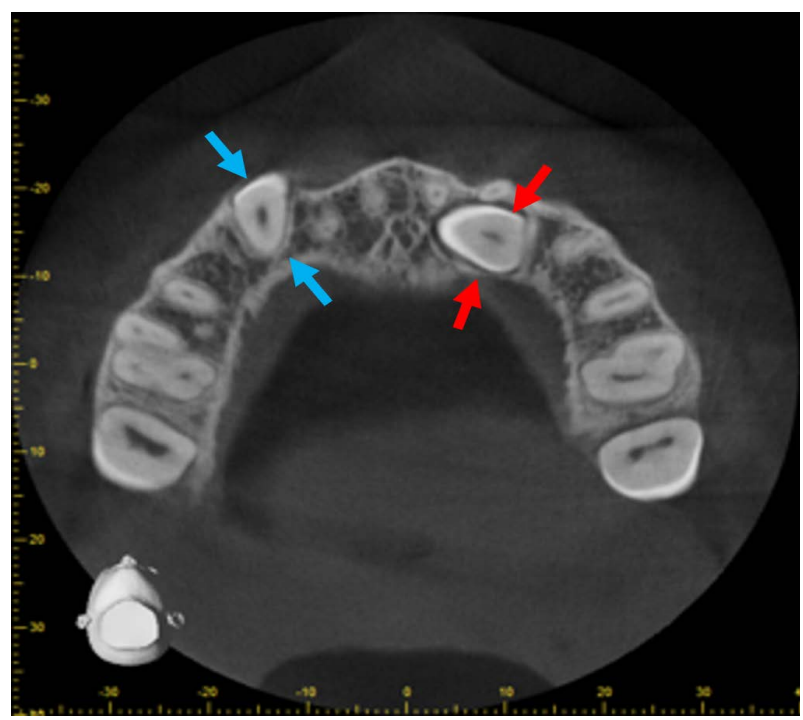

Figure 3. Axial Slice of the patient's CBCT images revealed the bucco-palatinal location of the right impacted maxillary canine (blue arrow) and the left impacted maxillary canine (red arrow).

and mouthwash were prescribed to the patient. Sutures were removed at the end of the first week after operation and no complications were observed. The patient is being followed for 2 years without any clinical sypmtoms and complications.

\section{Discussion}

After third molars, maxillary canines are the most frequently impacted teeth [14] and it is a usual finding of an oral pathology which stands for the $2 \%$ of the patients who is in need of an orthodontic treatment [15] [16]. Our patient refused the orthodontic treatment hence extractions of the teeth were decided. Noticing the early symptoms of canine impaction is crucial in order to prevent orthodontic problems and delayed orthodontic treatment. Knowing the mean eruption age of the canines is the first step of prevention. While 12 years and 3 months is the 


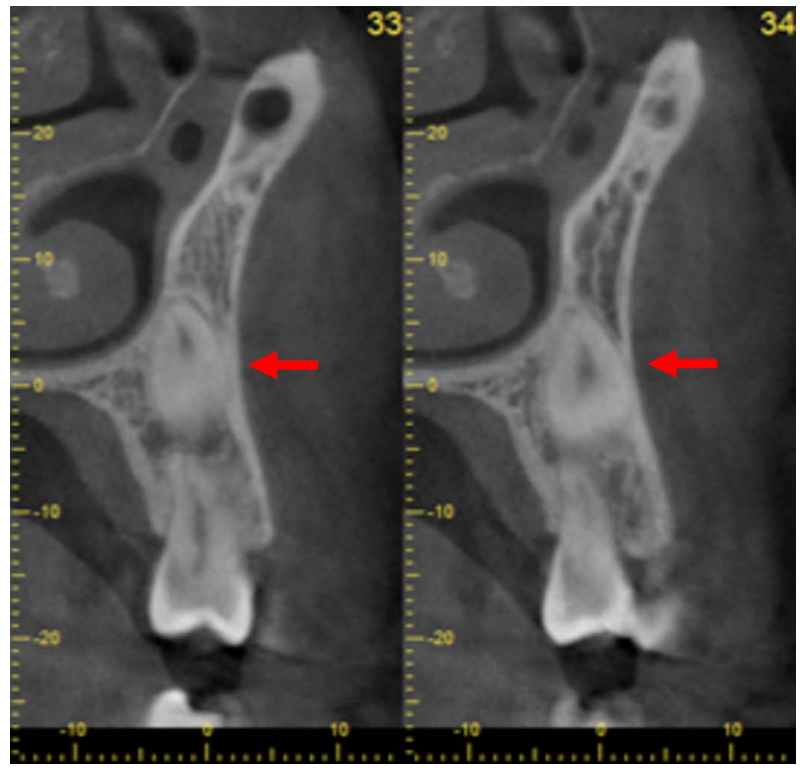

Figure 4. Cross-section image of the maxillary right canine (red arrow) was determined at the labial site.

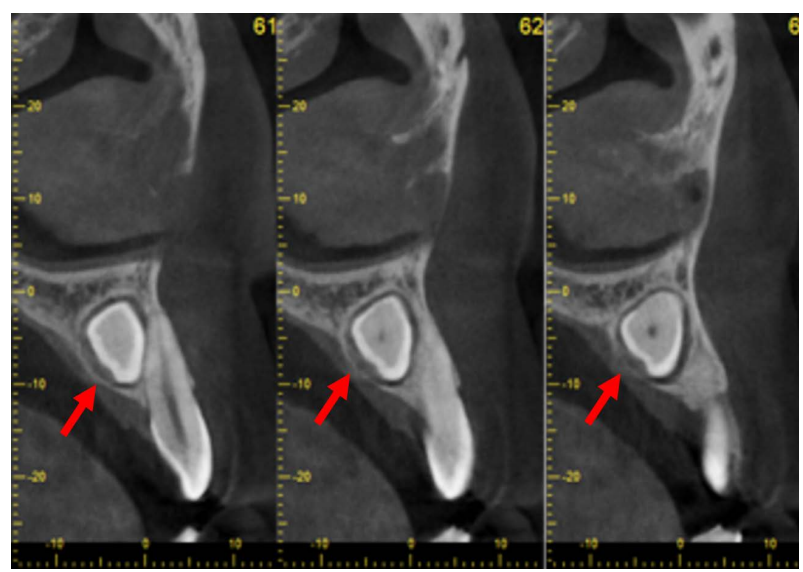

Figure 5. Cross-section image of the maxillary left canine (red arrow) was determined at the palatinal site.

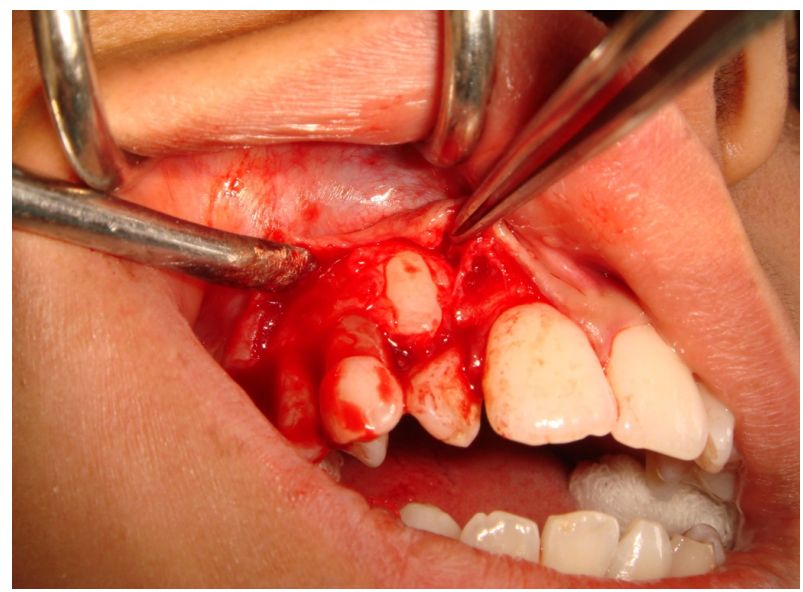

Figure 6. The mucoperiosteal vestibule flap was removed. 


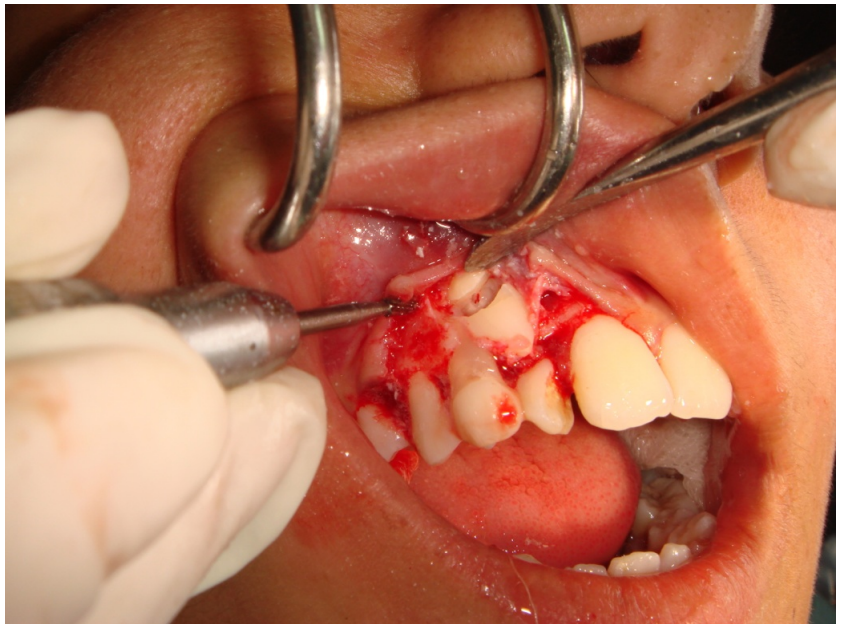

Figure 7. The tooth was removed by dividing into two pieces.

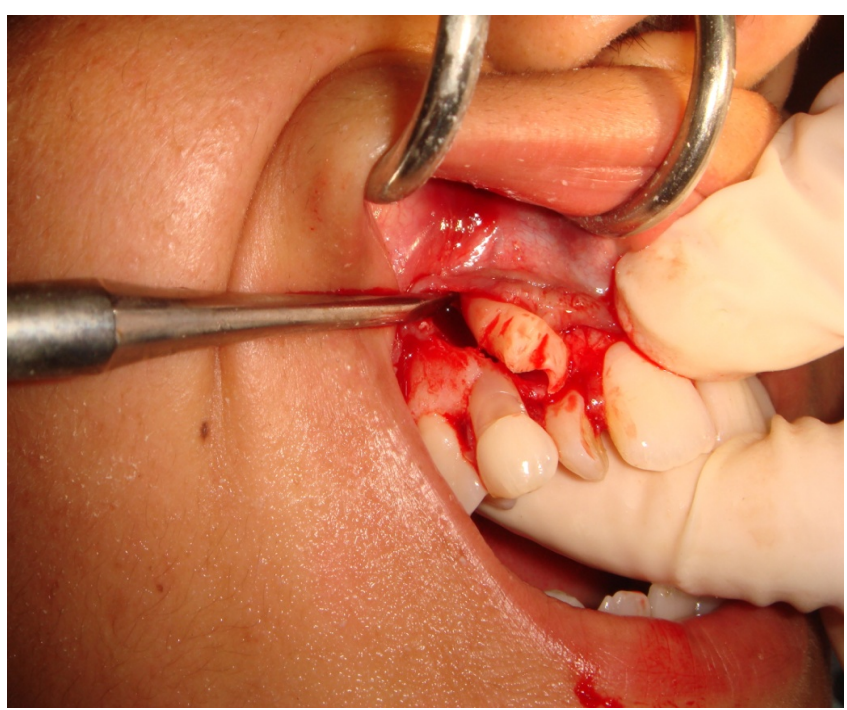

Figure 8. Removal of impacted right canine.

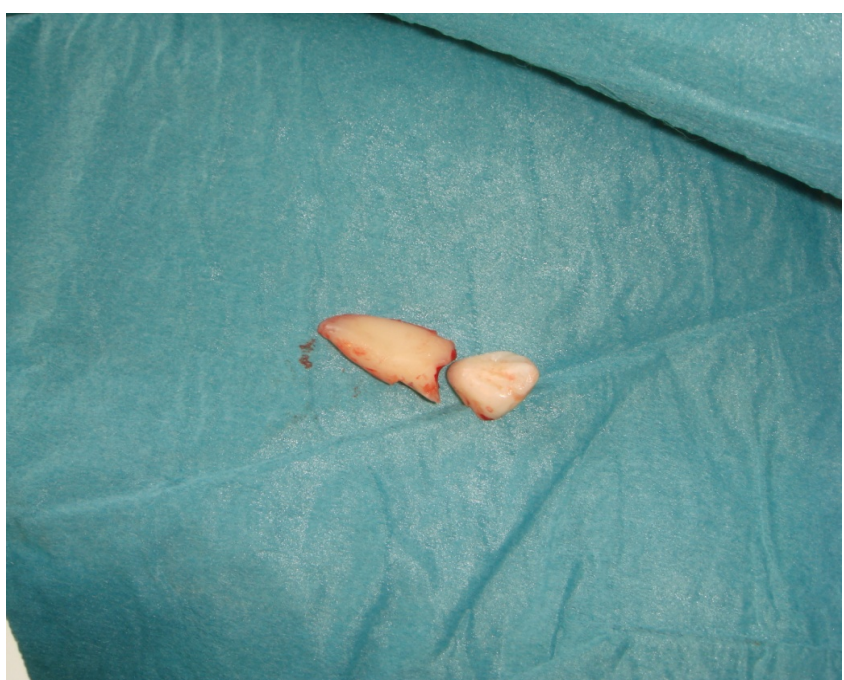

Figure 9. Extracted tooth. 


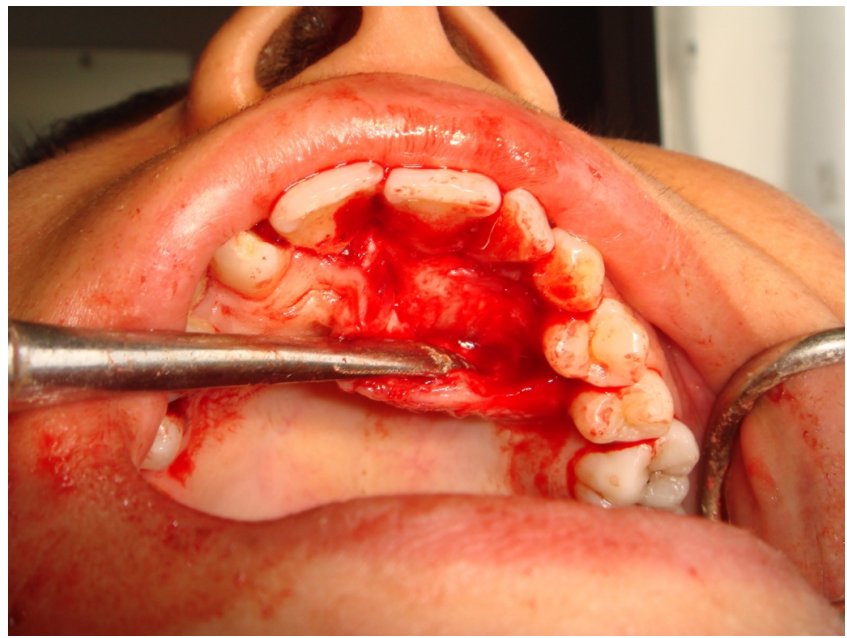

Figure 10. The mucoperiosteal palatinal flap was removed.

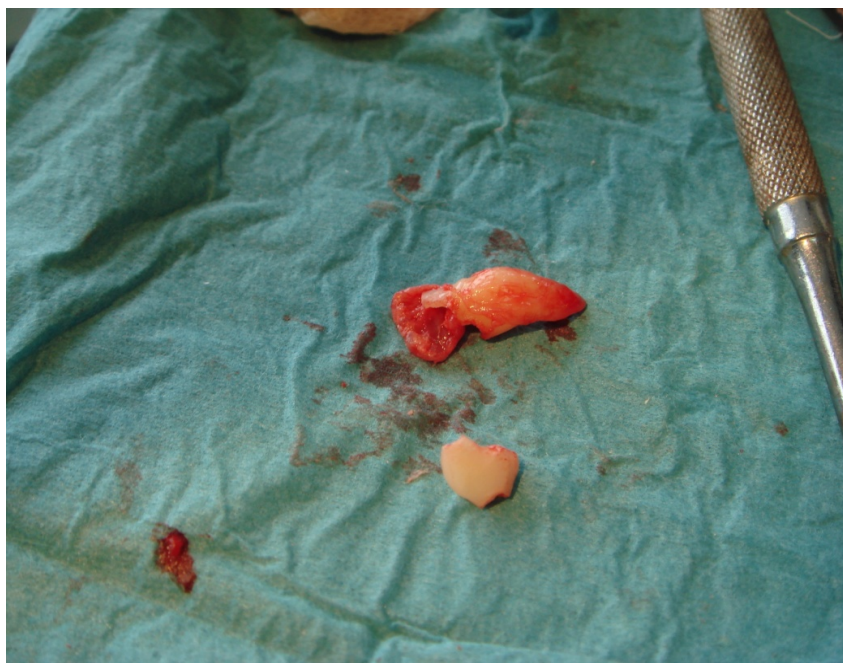

Figure 11. The tooth was removed by dividing into two pieces.

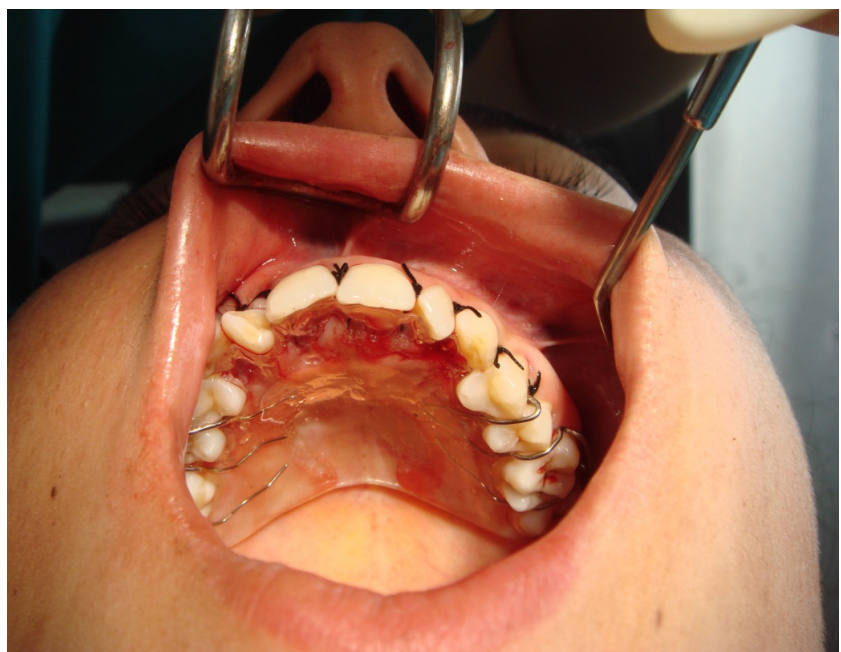

Figure12. Palatinal plaque prepared before surgical operation was placed in the patient. 
mean age of the maxillary canine eruption for the girls, 13 years is the mean age for the boys [2]. Understanding the formation of early mixed dentition is necessary so as to detect any anomaly such as peg-shaped tooth, enamel hypoplasia, missing incisors etc., which may affect the permanent dentition [17] [18] [19] [20] [21]. There was not a sign of any dental anomaly in our patient. Canine impaction is more frequent in females (than males), palatal region (than buccal region), and maxilla (than mandible). Unilateral impactions are more common than bilateral impactions [22] [23]. In our case, both impacted canines were located in the maxilla and the patient was a female however the impactions were bilateral. One canine was localized at the palatal region while the other canine was localized at the buccal region.

In general, the causes for retarded eruption of teeth may be either generalized or localized [5] [6]. Generalized causes include endocrine deficiencies and irradiation, among others. Our patient did not have any of these generalized causes.

The most common causes for canine impactions are usually local conditions and are the result of any one or a combination of the following factors: abnormal tooth position of the tooth bud, prolonged retention or early loss of deciduous canine, tooth size-arch length discrepancies, ankylosis, dilaceration of the root, the presence of an alveolar cleft, iatrogenic, trauma [7]. Localised cause of our case is probably prolonged retention of the teeth because deciduous maxillary canines were persisted.

In a research evaluating the spatial accuracy of CBCT, it was declared that $\mathrm{CBCT}$ is functional at measuring the size of the follicle and bone surrounding the tooth plus locating the bucco-palatal position of the impacted teeth and proximity of adjacent teeth [24]. In a research comparing traditional 2D images to CBCT images, $21 \%$ discrepancy was found in the mesio-distal location and $16 \%$ in the palato-labial localization of the impacted maxillary canines [25]. Thanks to CBCT images we foresaw that there will be a defect at the palatinal side after the extraction, thus, we prepared a palatinal plaque. The plaque also prevented the flap from sagging and it prevented the flap's necrosis.

The maxillary impacted right canine caused a swelling at the related region so it is easy to predict that the tooth was localised at the buccal region but it is impossible to know If the tooth was in contact with the palatal side of the maxillary. In this instance, with the contributions of CBCT images, we could be able to determine the exact position of the both impacted canines and a less invasive surgery was done. Conventional images such as orthopantomographic image would be insufficient to evaluate the position of the teeth which will cause a wider surgical area.

Reviews and case reports about impacted canines mostly emphasise following statements [25] [26] [27].

- $\mathrm{CBCT}$ is superior to conventional radiographs such as periapical radiography and orthopantomography for detecting and visualizing the positions and complications of maxillary impacted canines. 
- Traditional radiographs cannot provide adequate information about the bucco-palatinal positions of impacted teeth.

CBCT's radiation dose is much lower than Conventional CT systems; however, it is 4 to 15 times higher than a single orthopantomographic radiograph [28]. Unless we believe having СВСТ scans are necessary for the surgery, no advanced imaging technique should be performed.

\section{Conclusion}

Impacted canines are a common clinic condition which requires a multi-discipliner approach. $\mathrm{CBCT}$ can increase the success of the treatment with determining the proximity of the anatomical structures and the localization of the impacted teeth. There were no sign of complication and the healing was optimal.

\section{Conflicts of Interest}

The authors declare no conflicts of interest regarding the publication of this paper.

\section{References}

[1] Litsas, G. (2011) A Review of Early Displaced Maxillary Canines: Etiology, Diagnosis and Interceptive Treatment. The Open Dentistry Journal, 5, 39-47.

[2] Bishara, S.E., Kommer, D.D., McNeil, M.H., et al. (1976) Management of Impacted Canines. American Journal of Orthodontics, 80, 173-190.

[3] Moyers, R.E. (1963) Handbook of Orthodontics. 2nd Edition, Year Book Medical Publishers, Chicago, IL, 83-88.

[4] Brin, I., Solomon, Y. and Zilberman, Y. (1993) Trauma as a Possible Etiologic Factor in Maxillary Canine Impaction. American Journal of Orthodontics and Dentofacial Orthopedics, 104, 132-137. https://doi.org/10.1016/S0889-5406(05)81002-9

[5] Bishara, S.E. and Ortho, D. (1992) Impacted Maxillary Canines: A Review. American Journal of Orthodontics and Dentofacial Orthopedics, 101, 159-171. https://doi.org/10.1016/0889-5406(92)70008-X

[6] Ericson, S. and Kurol, J. (1988) Early Treatment of Palatally Erupting Maxillary Canines by Extraction of the Primary Canines. European Journal of Orthodontics, 10 , 283-295. https://doi.org/10.1093/ejo/10.1.283

[7] Mitchell, L. (2007) An Introduction to Orthodontics. 3rd Edition, Oxford University Press, New York, 147-156.

[8] Wanzeler, A.M., Marinho, C.G., Alves Junior, S.M., Manzi, F.R. and Tuji, F.M. (2015) Anatomical Study of the Canalis Sinuosus in 100 Cone Beam Computed Tomography Examinations. Oral and Maxillofacial Surgery, 19, 49-53. https://doi.org/10.1007/s10006-014-0450-9

[9] Von Arx, T., Lozanoff, S., Sendi, P. and Bornstein, M.M. (2013) Assessment of Bone Channels Other Than the Nasopalatine Canal in the Anterior Maxilla Using Limited Cone Beam Computed Tomography. Surgical and Radiologic Anatomy, 35 783-790. https://doi.org/10.1007/s00276-013-1110-8

[10] Tanaka, R., Hayashi, T., Ohshima, H., Ida-Yonemochi, H., Kenmotsu, S. and Ike, 
M. (2011) CT Anatomy of the Anterior Superior Alveolar Nerve Canal: A Macroscopic and Microscopic Study. Oral Radiology, 27, 93-97. https://doi.org/10.1007/s11282-011-0067-8

[11] Neves, F.S., Crusoé-Souza, M., Franco, L.C., Caria, P.H., Bonfim-Almeida, P. and Crusoé-Rebello, I. (2012) Canalis Sinuosus: A Rare Anatomical Variation. Surgical and Radiologic Anatomy, 34, 563-566. https://doi.org/10.1007/s00276-011-0907-6

[12] Torres, M.G., de Faro Valverde, L., Vidal, M.T. and Crusoé-Rebello, I.M. (2015) Branch of the Canalis Sinuosus: A Rare Anatomical Variation-A Case Report. Surgical and Radiologic Anatomy, 37, 879-881. https://doi.org/10.1007/s00276-015-1432-9

[13] Oliveira-Santos, C., Rubira-Bullen, I.R., Monteiro, S.A., León, J.E. and Jacobs, R. (2013) Neurovascular Anatomical Variations in the Anterior Palate Observed on CBCT Images. Clinical Oral Implants Research, 24, 1044-1048. https://doi.org/10.1111/j.1600-0501.2012.02497.x

[14] Shah, R.M., Boyd, M.A. and Vakil, T.F. (1978) Studies of Permanent Tooth Anomalies in 7886 Canadian Individuals. Journal of the Canadian Dental Association, 44, 262-264.

[15] Langberg, B.J. and Peck, S. (2000) Adequacy of Maxillary Dental Arch Width in Patients with Palatally Displaced Canines. American Journal of Orthodontics and Dentofacial Orthopedics, 118, 220-223. https://doi.org/10.1067/mod.2000.104819

[16] Shapira, J., Chaushu, S. and Becker, A. (2000) Prevalence of Tooth Transposition, Third Molar Agenesis, and Maxillary Canine Impaction in Individuals with Down Syndrome. The Angle Orthodontist, 70, 290-296.

[17] Baccetti, T. (1998) A Controlled Study of Associated Dental Anomalies. The Angle Orthodontist, 68, 267-264.

[18] Peck, S., Peck, L. and Kataja, M. (2002) Concomitant Occurrence of Canine Malposition and Tooth Agenesis: Evidence of Orofacial Genetic Fields. American Journal of Orthodontics and Dentofacial Orthopedics, 122, 657-660. https://doi.org/10.1067/mod.2002.129915

[19] Mercuri, E., Cassetta, M., Cavallini, C., Vicari, D., Leonardi, R. and Barbato, E. (2013) Dental Anomalies and Clinical Features in Patients with Maxillary Canine Impaction. The Angle Orthodontist, 83, 22-28. https://doi.org/10.2319/021712-149.1

[20] Shalish, M., Peck, S., Wasserstein, A. and Peck, L. (2010) Increased Occurrence of Dental Anomalies Associated with Infraocclusion of Deciduous Molars. The Angle Orthodontist, 80, 440-445. https://doi.org/10.2319/062609-358.1

[21] Becker, A. and Chaushu, S. (2015) Etiology of Maxillary Canine Impaction: A Review. American Journal of Orthodontics and Dentofacial Orthopedics, 148, 557-567. https://doi.org/10.1016/j.ajodo.2015.06.013

[22] Ericson, S. and Kurol, J. (1988) Radiographic Examination of Ectopically Erupting Maxillary Canines. American Journal of Orthodontics and Dentofacial Orthopedics, 91, 483-492. https://doi.org/10.1016/0889-5406(87)90005-9

[23] Dachi, S.F. and Howell, F.V. (1961) A Survey of 3874 Routine Full Mouth Radiographs: II. A Study of Impacted Teeth. Oral Surgery, Oral Medicine, Oral Pathology and Oral Radiology, 14, 1165-1169.

https://doi.org/10.1016/0030-4220(61)90204-3

[24] Walker, L., Enciso, R. and Mah, J. (2005) Three-Dimensional Localization of Maxillary Canines with Cone-Beam Computed Tomography. American Journal of Orthodontics and Dentofacial Orthopedics, 128, 418-423. 
https://doi.org/10.1016/j.ajodo.2004.04.033

[25] Haney, E., Gansky, S.A., Lee, J.S., et al. (2010) Comparative Analysis of Traditional Radiographs and Cone-Beam Computed Tomography Volumetric Images in the Diagnosis and Treatment Planning of Maxillary Impacted Canines. American Journal of Orthodontics and Dentofacial Orthopedics, 137, 590-597. https://doi.org/10.1016/j.ajodo.2008.06.035

[26] Katheria, B.C., Kau, C.H., Tate, R., Chen, J.W., English, J. and Bouquot, J. (2009) Effectiveness of Impacted and Supernumerary Tooth Diagnosis from Traditional Radiography versus Cone Beam Computed Tomography. Pediatric Dentistry, 32, 304-309.

[27] Nagpal, A., Pai, K.M., Setty, S. and Sharma, G. (2009) Localization of Impacted Maxillary Canines Using Panoramic Radiography. Journal of Oral Science, 51, 37-45.

[28] Olive, R.J. (2005) Factors Influencing the Non-Surgical Eruption of Palatally Impacted Canines. Australasian Orthodontic Journal, 21, 95-101. 